\title{
Walking-Evoked Erection in Patients with Lumbar Degenerative Diseases: Eight Cases and Review of the Literature
}

\author{
Kengo Hirota ${ }^{1,2}$, Junya Hanakita ${ }^{1}$, Toshiyuki Takahashi ${ }^{1}$, Ryo Kanematsu ${ }^{1}$, \\ Manabu Ueno ${ }^{3}$, Hidetoshi Kasuya ${ }^{2}$, Manabu Minami ${ }^{1}$ \\ ${ }^{1}$ Spinal Disorders Center, Fujieda Heisei Memorial Hospital, Shizuoka, Japan \\ ${ }^{2}$ Department of Neurosurgery, Tokyo Women's Medical University Medical Center East, Tokyo, Japan \\ ${ }^{3}$ Department of Urology, Fujieda Heisei Memorial Hospital, Shizuoka, Japan
}

Study Design: Narrative review with a case illustration.

Purpose: The purpose of this study was to evaluate the pathogenesis and outcome of therapy for walking-evoked erection in patients with lumbar degenerative diseases.

Overview of Literature: Cauda equina compression due to lumbar degenerative diseases rarely cause a walking-evoked erection; however, no review has been undertaken of walking-evoked erection in patients with lumbar degenerative diseases.

Methods: A total of 1,570 male patients with lumbar degenerative diseases, who underwent surgery between April 2003 and June 2017, were evaluated; from these patients, participants with walking-evoked erection were selected. Preoperative clinical data of walking-evoked erection, paresthesia, and bladder and bowel function were assessed. In our study, the neurological status and the erectile function of each participant were retrospectively evaluated before and after surgery using the Japanese Orthopedic Association score and the Overactive Bladder Symptom Score.

Results: Among the 1,570 male patients screened in our department, eight patients $(0.51 \%, 8 / 1,570)$ presented with walking-evoked erection accompanied by cauda equina symptoms. In six of the patients, the erectile symptoms were associated with paresthesia in the genitalia or perianal region. Of the six patients evaluated for bladder dysfunction, all were diagnosed with prostatic hyperplasia, while four were diagnosed with an overactive bladder. In all patients, walking-evoked erection disappeared entirely after surgery. Conclusions: This study comprises the first review of walking-evoked erection in patients with lumbar degenerative diseases. We speculate that sensory input, such as paresthesia in the genitalia or perianal region stimulates the pelvic or perineal nerves through the pudendal nerve and induces reflexogenic erections.

Keywords: Lumbar spinal stenosis; Priapism; Penile erection; Cauda equina symptoms; Reflexogenic erections

\section{Introduction}

Characteristic clinical symptoms of lumbar degenerative diseases include intermittent claudication, low back pain, and leg pain. The condition is often exacerbated on standing, walking, or lumbar extension and can be relieved by

Received Oct 29, 2019; Revised Feb 27, 2020; Accepted Mar 2, 2020

Corresponding author: Kengo Hirota

Department of Neurosurgery, Tokyo Women’s Medical University Medical Center East, 2-1-10 Nishiogu, Arakawa-ku, Tokyo, 116-8567, Japan

Tel: +81-3-3810-1111, Fax: +81-3-3819-8680, E-mail: k2bumps@gmail.com 
forwards-flexion or by sitting [1-3]. Lumbar degenerative diseases also cause bowel, bladder, and erectile dysfunction [4]. Walking and flexion of the lumbar spine, such as sitting forwards, can aggravate walking-evoked erection, and symptoms can be relieved by resting for several minutes. The pathogenesis of walking-evoked erection is unclear; consequently, it is rarely noticed. It has been reported that urge incontinence due to an overactive bladder may be stimulated during walking; this mechanism is similar to the mechanism of development of a walkingevoked erection [5]. In this study, we examined patients with lumbar degenerative diseases and evaluated the pathogenesis and the treatment outcomes of walkingevoked erection and bladder dysfunction.

\section{Materials and Methods}

A total of 1,570 male patients from our department with lumbar degenerative diseases including lumbar spinal stenosis, lumbar disk herniation, and spondylolisthesis underwent surgery between April 2003 and June 2017, of these, eight patients presented with walking-evoked erection. The Ethical Committee of Fujieda Heisei Memorial Hospital approved the study protocols (reference no., FHR 28-6). We examined the clinical data of walking-evoked erection, paresthesia, motor dysfunction, bladder, and bowel dysfunction. The neurological status of each participant, before and after surgery, was assessed using the Japanese Orthopedic Association (JOA) score. A urologist examined six patients for evaluation for prostatic hyper- plasia and overactive bladder. Patients with a score $>5$ on the Overactive Bladder Symptom Score (OABSS) were classified as having an overactive bladder [6]. Prostatic hyperplasia was diagnosed using prostatic echo. Lumbar magnetic resonance imaging (MRI) was used for the diagnosis of lumbar degenerative diseases. With regards to surgical treatment, a discectomy was completed for disk herniation, and one- or two-level partial laminectomy was performed in patients with lumbar spinal stenosis. Patients with lumbar disk herniation and spondylolisthesis accompanied by segmental instability underwent posterior lumbar interbody fusion (PLIF) and transformational lumbar interbody fusion (TLIF). Follow-up of all patients lasted for at least 6 months after surgery.

Subsequently, a PubMed search was conducted in May 2019 to identify all studies on walking-evoked erection in English with no publishing year restriction. Clinical articles and case reports were searched, and the reference lists were screened for additional relevant articles. Search terms used were: "lumbar spinal stenosis," "erection," and "intermittent priapism." These terms were combined using the algorithmic terms "AND" to retrieve relevant study titles of reports and abstracts. Additionally, reference lists of the selected articles were further screened to highlight other referenced studies not identified in the original search. Inclusion criteria were: English language studies, case reports, and reviews, including detailed clinical data of the patient, imaging data, and outcome after surgery; abstract; and full-text availability. We selected only surgical cases with walking-evoked erection accompanied by

Table 1. Clinical features of our cases

\begin{tabular}{|c|c|c|c|c|c|c|c|c|c|c|c|}
\hline Case & $\begin{array}{l}\text { Age } \\
\text { (yr) }\end{array}$ & $\begin{array}{l}\text { Duration from } \\
\text { symptoms to } \\
\text { surgery (mo) }\end{array}$ & $\begin{array}{l}\text { Intermittent } \\
\text { claudication } \\
\text { (m) }\end{array}$ & $\begin{array}{c}\text { Muscle } \\
\text { weakness }\end{array}$ & Numbness in legs & $\begin{array}{c}\text { Paresthesia } \\
\text { in genitalia or } \\
\text { perianal }\end{array}$ & PTR & ATR & $\begin{array}{l}\text { JOA } \\
\text { score }\end{array}$ & OABSS & $\mathrm{OAB}$ \\
\hline 1 & 57 & 120 & 50 & - & Bilateral S1 areas & + & $+/+$ & $-/-$ & 15 & 0 & - \\
\hline 2 & 59 & 40 & 100 & - & Left S1 area & + & $+/+$ & $-/-$ & 17 & 6 & + \\
\hline 3 & 66 & 29 & 100 & - & Bilateral S1 areas & + & +t/++ & $\pm / \pm$ & 4 & 12 & + \\
\hline 4 & 62 & 24 & 50 & - & Bilateral S1 areas & + & $+/+$ & $\pm / \pm$ & 7 & 5 & + \\
\hline 5 & 77 & 7 & 100 & - & Bilateral S1 areas & - & $+/+$ & $-/-$ & 13 & 8 & + \\
\hline 6 & 81 & 360 & 30 & - & Bilateral L5 and S1 areas & + & t/+ & $\pm / \pm$ & 16 & 4 & - \\
\hline 7 & 69 & 12 & 100 & - & Bilateral L5 and S1 areas & + & $\pm / \pm$ & $\pm / \pm$ & 14 & NA & NA \\
\hline 8 & 61 & 72 & 50 & - & Bilateral L5 and S1 areas & + & $+/+$ & $-/-$ & 20 & NA & NA \\
\hline
\end{tabular}

PTR, patellar reflex; ATR, achilles reflex; JOA, Japanese Orthopedic Association; OABSS, Overactive Bladder Symptom Score; OAB, overactive bladder; NA, not available. 
cauda equina symptoms.

\section{Results}

Among the 1,570 patients screened in our department, eight patients presented with walking-evoked erection accompanied with cauda equina symptoms. The clinical background of the eight patients with walking-evoked erection is shown in Table 1 and Table 2.

\section{Patient characteristics}

Eight participants were included in this study; the average age was 67 years (range, $57-81$ years). The median duration from initial cauda equina symptoms to admission for surgery was 83 months (range, 7-360 months). Walking approximately $72.5 \mathrm{~m}$ (range, 30-100 m) caused intermittent claudication. All patients had an erection while walking and resting for several minutes, relieved the symptoms. Out of the eight patients, seven had paresthesia in the genitalia or perianal region and developed walkingevoked erection accompanying the paresthesia. In all participants, numbness occurred from the back of the thigh to the bottom of the foot ( $\mathrm{S} 1 \mathrm{area}$ ), and the Achilles reflex was diminished or absent. The average JOA score was 13.5 points (range, $4-20$ points). Bladder dysfunction was evaluated in six of the patients; all were diagnosed with prostatic hyperplasia, while four were diagnosed with an overactive bladder.

\section{Radiographical findings}

Of the eight patients, MRI, or myelography showed lumbar canal stenosis in four patients, spondylolisthesis in two patients, and disc herniation in two patients. Pathological changes were noticed in one patient at $\mathrm{L} 3 / 4$, in four patients at $\mathrm{L} 4 / 5$, and in three patients at $\mathrm{L} 3 / 4$ and L4/5 levels.

\section{Treatment}

A total of three patients underwent lumbar decompression surgery, and five patients underwent fusion surgery (PLIF or TLIF). Of the participants, five experienced a single-level decompression, and three underwent a twolevel decompression. No complications, such as nerve root injuries, were observed after surgery in any of the patients.

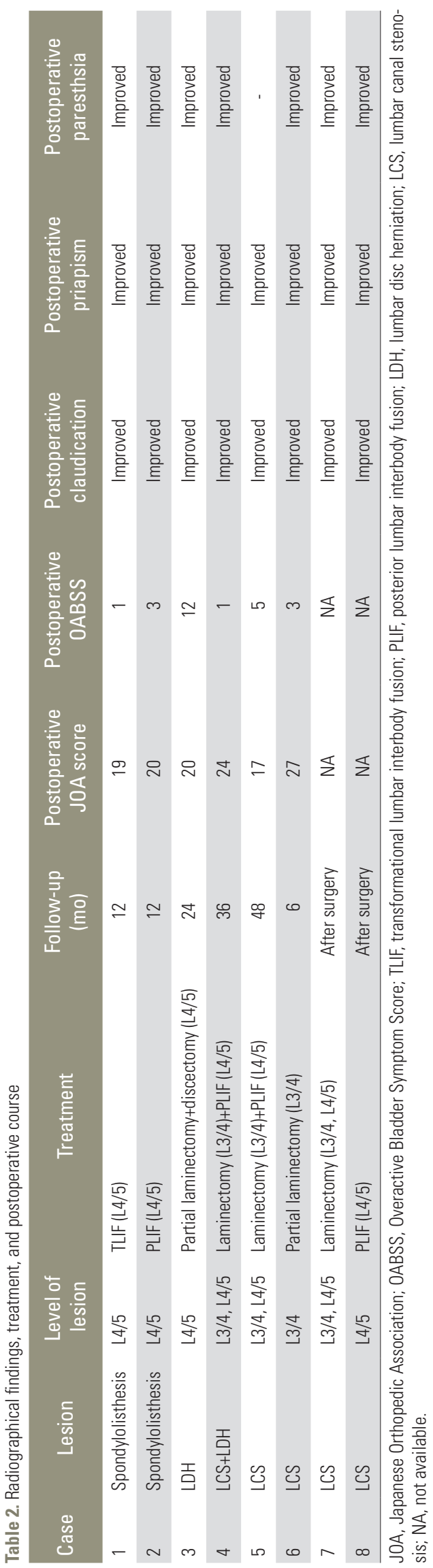




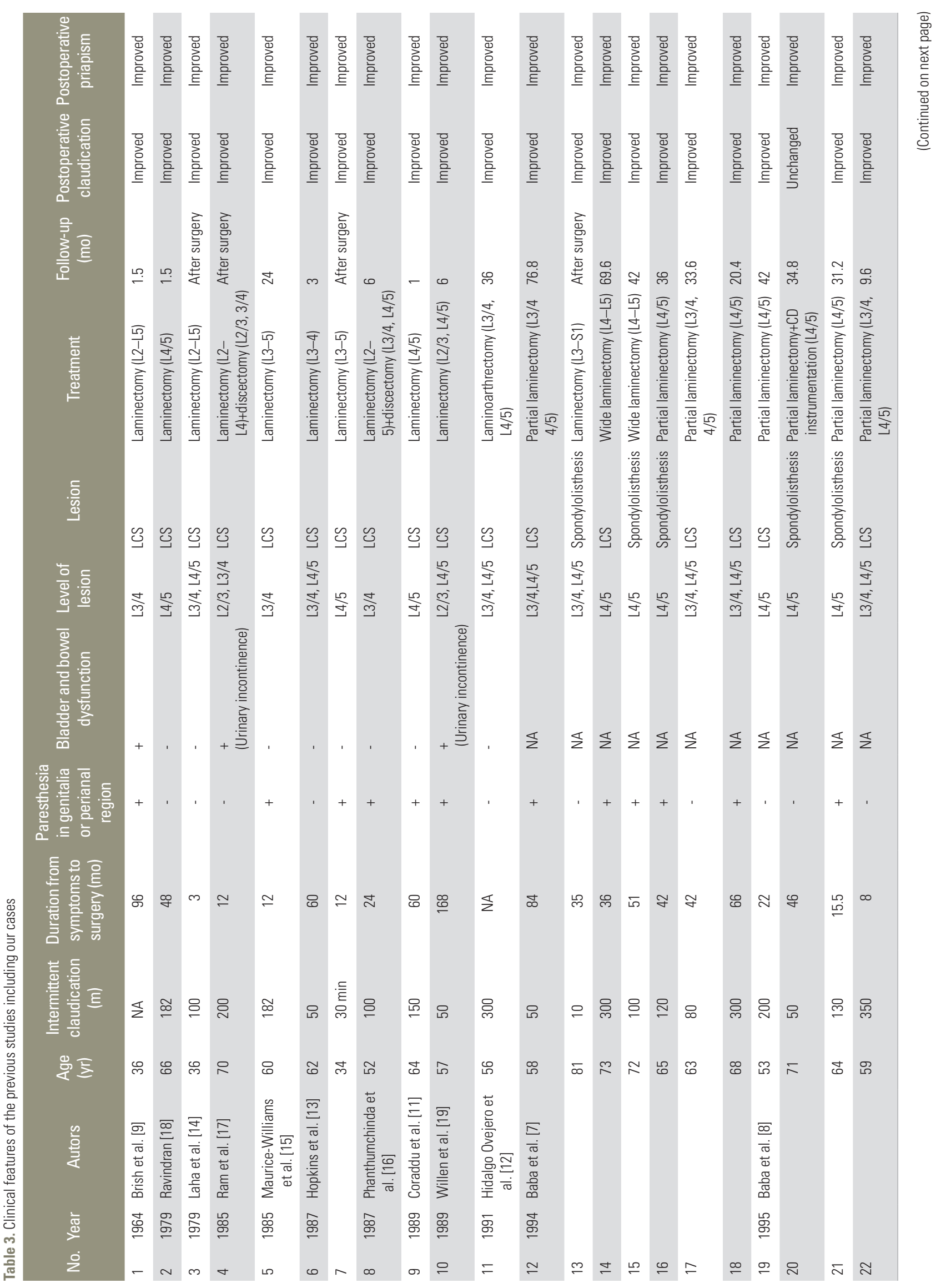




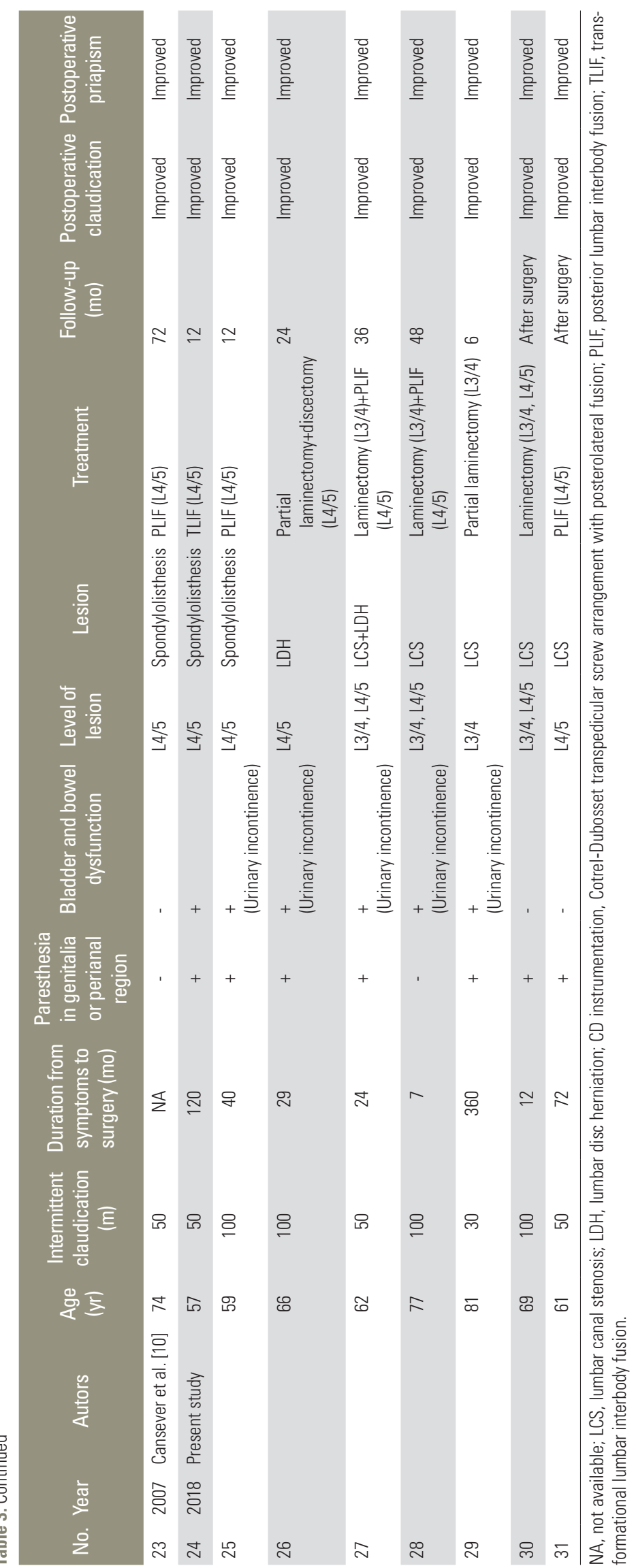




\section{Postoperative course}

The median follow-up time after surgery was 23 months (range, 0-48 months). After surgery, all patients experienced a complete disappearance of walking-evoked erection. Paresthesias in the genitalia or perianal region disappeared in seven patients. JOA scores improved in six patients; however, two patients did not experience an improved score. OABSS improved in four patients.

\section{Literature search}

The initial PubMed search yielded 22 reports; six additional studies were identified from reference lists of the selected articles. Duplicates were checked and discarded. As a result, 23 patients, including 13 reports, were included in our study (Table 3) [7-19]. A total of 31 patients, including the eight participants in our study, were included, the average age being 62.1 years (range, $34-81$ years). The median duration from any initial cauda equina symptoms to admission for surgery was 55.4 months (range, 3-360 months). Intermittent claudication was caused by walking approximately $121 \mathrm{~m}$ (range, $10-350 \mathrm{~m}$ ). Nineteen patients $(61.3 \%)$ had paresthesia in the genitalia or perianal region. Bladder dysfunction was demonstrated in nine of the patients $(29 \%)$, seven of which had urinary incontinence. In total, 26 patients underwent lumbar decompression surgery, and five patients underwent fusion surgery (PLIF or TLIF). The median follow-up after surgery was 22.1 months (range, 0-76.8 months) in all 31 patients. Walking-evoked erection disappeared completely after surgery in all patients.

\section{Discussion}

This study comprises the first review of walking-evoked erection in patients with lumbar degenerative diseases. It was first described in 1964 by Brish et al. [9]; followed by several other authors [7-19]. The central finding of the study shows that in patients with lumbar degenerative diseases, the incidence of walking-evoked erection was $0.51 \%$ $(8 / 1,570)$. Furthermore, surgical intervention proved successful in the study participants, as walking-evoked erection disappeared after treatment.

\section{Epidemiology and clinical futures}

Baba et al. [7] reported that the incidence of walkingevoked erection in patients with lumbar degenerative diseases was $1.8 \%$ (9/487), in our study, the incidence were lower at $0.51 \%(8 / 1,570)$. Intermittent claudication is the most specific symptom of central lumbar canal stenosis; intermittent claudication consists of the progressive onset of pain, numbness, weakness, and tingling in the low back, buttocks, and legs, which can be initiated by standing, walking, or lumbar extension [20]. Intermittent claudication in this study was caused by walking a median of $121 \mathrm{~m}$, thus indicating severe grade lumbar canal stenosis. Additionally, paresthesia in the genital and perianal region as an accompanying symptom was confirmed to be highly prevalent in patients with walking-evoked erection; the frequency was $87.5 \%$ in our participants. An erection accompanied by paresthesia in the genital and perianal region is a characteristic symptom.

\section{Pathogenesis}

Penile erection is the result of a complex interaction of psychological, neural, vascular, and endocrine factors. Stimulation for erection can be classified as psychogenic (visual, olfactory, gustatory, etc.) and reflexogenic (stimulation of the glans penis) [21]. Reflexogenic erection is triggered by direct physical stimulation of the genital organs and involves two reflex loops. (1) The pudendacavernosal reflex loop initiates reflexogenic erection: the dorsal nerve of the penis sends afferent sensory information to the sacral erection center S2-4, and the efferent cavernous nerves, through the pelvic nerve, initiate arterial vasodilatation in the erectile tissues of the penis leading to tumescence. (2) In the bulbocavernosus reflex loop, the dorsal nerve of the penis sends afferent sensory information from the penis to the sacral erection center S2-4, while efferent motor neurons travel via the pudendal nerve to the bulbocavernosus muscles [22]. The stimulus for reflexogenic erection comes from external sources such as rubbing paresthesia in the genitalia or perianal region. The functional neuroanatomy of penile erection is shown in Fig. 1.

Walking-evoked erection is involved in reflexogenic erection, the pathogenesis of which is unclear. Previous reports have suggested two hypotheses for walkingevoked erection; one report suggested that compression 


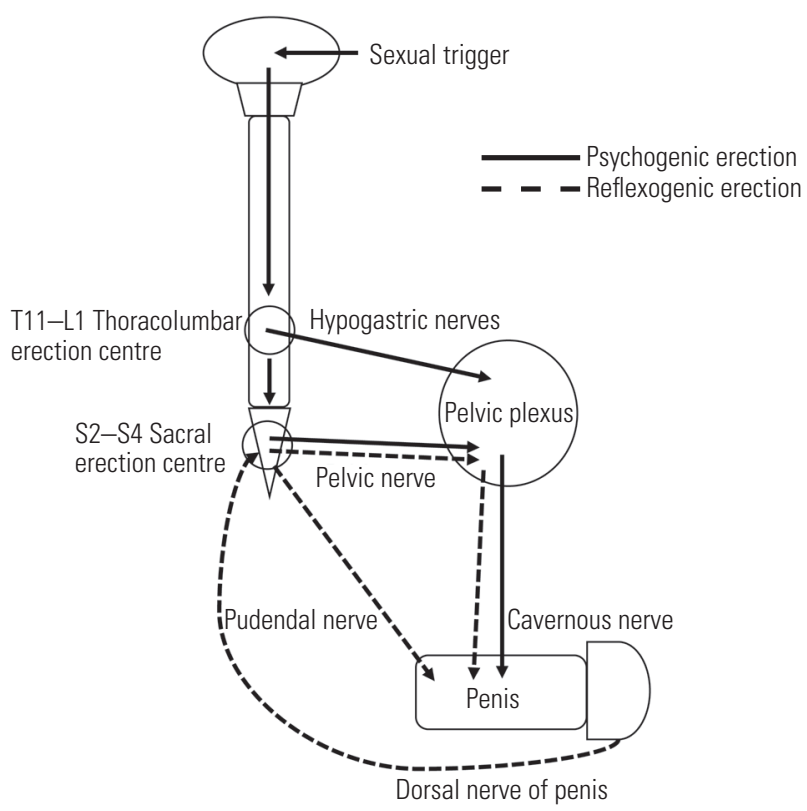

Fig. 1. Functional neuroanatomy of penile erection. Direct stimulation of the penis delivers sensory messages to the spinal cord via $\$ 2-\$ 4$, and then signals traveling from the spinal cord to the penis cause reflexogenic erection. Psychogenic erection is regulated by a centrally connected thoracolumbar (T11-L1) and sacral (S2-4) erection center.

of the cauda equina with the S2-S4 roots in lumbar canal stenosis directly stimulates the pelvic nerve, resulting in the erection. Shintani et al. [23] speculated that walkingevoked erection is caused by intermittent mechanical compression of the cauda equina, which includes the efferent fibers of S2-S4 parasympathetic outflows; they describe posture induced ischemia and compression neuropathy of S2-S4 parasympathetic efferent fibers, causing the symptom of walking-evoked erection. Baba et al. [7] suggested that walking-evoked erection could disturb the circulation within the cauda equina due to increased cerebrospinal fluid pressure in the subarachnoid cavity. However, if mechanical compression of the cauda equina induces walking-evoked erection, its occurrence would be more frequent. However, as this study explains, the erection phenomenon is very rarely noticed. The hypothesis that that induction of erection has some inducing factors other than mechanical compression of the cauda equina is therefore supported. In our study, walking-evoked erection was observed to be accompanied by sensory manifestations such as paresthesia in the genitalia or perianal region; the paresthesia was observed in $61 \%$ (19 of 31) of patients.

Additionally, an overactive bladder has often been diagnosed in patients with lumbar degenerative diseases, the frequency of which is $21 \%-44 \%$, as per previous reports $[5,24]$. It is reported that walking may induce urge incontinence due to overactive bladder and often occurs after paresthesias in the genitalia or perianal region, the mechanism of which is similar to the development of walkingevoked erection. Interestingly, it has been reported that patients with lumbar canal stenosis had both erection and urge incontinence due to overactive bladder on walking [5]. A urologist evaluated the study participants for bladder function; four out of six patients had both urge incontinence due to overactive bladder, as well as erection on walking, three of which also had paresthesia on walking. The neural pathways of both urination and erection are similar, consisting of the pudendal nerve for genital or perianal sensory input. We speculate that sensory input, such as paresthesias in the genitalia or perianal region, stimulates the pelvic, or perineal nerves through the pudendal nerve and induces reflexogenic erections.

\section{Outcome}

Patients experienced no further occurrences of walkingevoked erection after surgery. Walking-evoked erection, as well as paresthesias in the genital or perianal region on walking, was eliminated in our patients. Our study followed eight patients, four of which showed an improved OABSS score. Patients with a poor outcome with regards to an overactive bladder in comparison with the outcome of walking-evoked erection were in part due to their having co-existent prostatic hyperplasia. In summary, lumbar decompression surgery plays a vital role in the treatment of walking-evoked erection

\section{Conclusions}

The prevalence of lumbar degenerative diseases is expected to increase with the prolonging of the human life span. Symptoms such as intermittent claudication and urogenital symptoms such as incontinence, impotence, and walking-evoked erection should be meticulously examined and treated in patients who present with lumbar degenerative disorders.

\section{Conflict of Interest}

No potential conflict of interest relevant to this article was reported. 


\section{Author Contributions}

$\mathrm{KH}$ performed the experiments and data analysis and drafted the manuscript. JH designed the study, interpreted the data and revised the manuscript for intellectual content. TT, RK, and MU recruited the participants and contributed to data analysis. HK and MM conducted and supervised this study, evaluated the data and revised the manuscript for intellectual content.

\section{References}

1. Binder DK, Schmidt MH, Weinstein PR. Lumbar spinal stenosis. Semin Neurol 2002;22:157-66.

2. Goh KJ, Khalifa W, Anslow P, Cadoux-Hudson T, Donaghy M. The clinical syndrome associated with lumbar spinal stenosis. Eur Neurol 2004;52:242-9.

3. Weinstein JN, Tosteson TD, Lurie JD, et al. Surgical versus nonsurgical therapy for lumbar spinal stenosis. N Engl J Med 2008;358:794-810.

4. Gempt J, Rothoerl RD, Grams A, Meyer B, Ringel F. Effect of lumbar spinal stenosis and surgical decompression on erectile function. Spine (Phila Pa 1976) 2010;35:E1172-7.

5. Yamanishi T, Yasuda K, Sakakibara R, Murayama N, Hattori T, Ito H. Detrusor overactivity and penile erection in patients with lower lumbar spine lesions. Eur Urol 1998;34:360-4.

6. Homma Y, Yoshida M, Seki N, et al. Symptom assessment tool for overactive bladder syndrome: overactive bladder symptom score. Urology 2006;68:318-23.

7. Baba H, Furusawa N, Tanaka Y, Imura S, Tomita K. Intermittent priapism associated with lumbar spinal stenosis. Int Orthop 1994;18:150-3.

8. Baba H, Maezawa Y, Furusawa N, Kawahara N, Tomita K. Lumbar spinal stenosis causing intermittent priapism. Paraplegia 1995;33:338-45.

9. Brish A, Lerner MA, Braham J. Intermittent claudication from compression of cauda equina by a narrowed spinal canal. J Neurosurg 1964;21:207-11.

10. Cansever T, Civelek E, Sencer A, Karasu A, Turan$\tan$ I. Intermittent priapism in degenerative lumbar spinal stenosis: case report. Turk Neurosurg 2007;17:260-3.

11. Coraddu M, Floris F, Corrias A, Nurchi GC, Lobina
GF, Dettori P. Spontaneous priapism produced by stenosis of the lumbar canal. Acta Neurol (Napoli) 1989;11:428-33.

12. Hidalgo Ovejero AM, Garcia Mata S, Sauras Herranz MA, Maravi Petri E, Martinez Grande M. Intermittent priapism in spinal stenosis. Acta Orthop Belg 1991;57:192-4.

13. Hopkins A, Clarke C, Brindley G. Erections on walking as a symptom of spinal canal stenosis. J Neurol Neurosurg Psychiatry 1987;50:1371-4.

14. Laha RK, Dujovny M, Huang PS. Intermittent erection in spinal canal stenosis. J Urol 1979;121:123-4.

15. Maurice-Williams RS, Marsh HT. Priapism as a feature of claudication of the cauda equina. Surg Neurol 1985;23:626-8.

16. Phanthumchinda K, Phonprasert C, Khaoroptham S. Priapism: a rare clinical manifestation of lumbar stenosis. J Med Assoc Thai 1987;70:604-7.

17. Ram Z, Findler G, Spiegelman R, Shacked I, Tadmor $\mathrm{R}$, Sahar A. Intermittent priapism in spinal canal stenosis. Spine (Phila Pa 1976) 1987;12:377-8.

18. Ravindran M. Cauda equina compression presenting as spontaneous priapism. J Neurol Neurosurg Psychiatry 1979;42:280-2.

19. Willen JG, Griffiths ER, Mastaglia FL, Beaver R. Intermittent parasympathetic symptoms in lumbar spinal stenosis. J Spinal Disord 1989;2:109-13.

20. Porter RW. Spinal stenosis and neurogenic claudication. Spine (Phila Pa 1976) 1996;21:2046-52.

21. Weiss HD. The physiology of human penile erection. Ann Intern Med 1972;76:793-9.

22. Overgoor ML, Braakhekke JP, Kon M, De Jong TP. Restoring penis sensation in patients with low spinal cord lesions: the role of the remaining function of the dorsal nerve in a unilateral or bilateral TOMAX procedure. Neurourol Urodyn 2015;34:343-8.

23. Shintani S, Shiozawa Z, Tsunoda S. Intermittent penile erection in lumbar canal stenosis. J Neurol 1988;235:188-9.

24. Watanabe M, Hanakita J, Takahashi T, Kuraishi K, Kawaoka T, Tominaga $\mathrm{T}$. The utility of the International Prostate Symptom Score (IPSS) for evaluating lower urinary tract symptoms (LUTS) in lumbar degenerative diseases. Jpn J Neruosurg 2013;22:699706. 